EPiC Series in Built Environment
Volume 1, 2020, Pages 99-107
Associated Schools of Construction Proceed-
ings of the 56th Annual International Conference

\title{
Student Learning Assessment from a Virtual Field Trip
}

\author{
Amna Salman, MCP, MPA, B. Arch \\ Auburn University \\ Auburn, Alabama
}

Teaching through field trips has been very effective as students learn more when they see the objects in reality. However, it is not always feasible to take a large class to field trips due to time, safety, and cost limitations. Creating 3D Virtual Reality (VR) models and immersing students in that virtual world could provide an engaging and meaningful experience to both building science and architecture students. The aim of this research was to see if Virtual Field Trips (VFTs) can replace actual field trips in times of need. For that reason, an app was created teaching students about steel connections called the Steel Sculpture App (SSA). The SSA served as VFT and the location of physical steel sculpture model served as the actual field trip. This paper focuses on student learning assessment and experience from of VFT versus the actual field trip. Scope of this study is limited to $3^{\text {rd }}$ year building science and architecture students who have attained basic knowledge of structural systems. The author used controlled group and experimental group method to analyze the learning assessment. The results indicated that the students learning from VFTs scored slightly higher than those learning from actual field trip. Although, students liked learning through the actual field trip but the VFT group was able to score better because they learnt without any distractions.

Key Words: Virtual Reality, Construction Education, Flipping Classroom, Pedagogical Changes, Steel Structures, Virtual Field Trips, Learning Assessments

\section{Introduction}

An educational field trip in the form of site visits is an integral part of construction education. Good field trips provide participants with first-hand experience related to the topic or concept being discussed in the class. However, instructors have to spend significant amount of time to plan them as well as avoid conflicts with other classes (Kim et.al, 2019). It is important to find an alternative rather than having no field trips because the ability to visualize the built environment and learn the building construction processes is critical for students in the architecture and construction disciplines (Salman, A, 2019). For students lacking field experience, visualizing the construction processes and thus making informed decisions is difficult (Nikolic et.al, 2011). Field trips, while valuable, are difficult to plan due to cost, safety, and time limitations. Creating 3D VR models and immersing students in that 
virtual world could provide an engaging and meaningful experience to both building science and architecture students (Salman, A, 2019). For this reason, through McWhorter Fund for Excellence award, we have created an interactive VR Oculus Go app, the "Steel Sculpture App (SSA)" to teach steel connections to building science and architecture students (Salman, A, 2019). Many schools in the USA have used a steel sculpture model for explaining connections. A steel sculpture is a physical system that shows different types of connections found in standard construction practices as shown in Figure 1. However, not all architecture and construction programs have the steel sculpture. Those schools which have the steel sculpture are unable to bring it in class due to its size and weight (eight feet tall, weighs nearly 2500 pounds and usually erected outdoor) (Moaveni and Chou, 2015).

The developmental phase and workability of the SSA is explained in a previously published paper by the author. This paper explains the second phase of the research in which we assess student learning through VFT. The SSA served as the VFT and the location of the actual steel sculpture model was considered an actual field trip. A controlled group and experimental group method is used to analyze student learning assessment. After the learning assessment all students were given a chance to experience both pedagogies to get their feedback.

The SSA is a self-explanatory interactive app which is also designed to cater people who have hearing impairment. In addition, to allow student's better understanding of the steel construction process, videos of the various assembly and erection processes are included in the final product. The SSA allows students to see modules again and again and can pause or exit any time. This interaction allowed by three dimensional (3D) geometric models could also bring an end to passive leaners' attitude which are often found in traditional academic teaching situations (Sampaio et.al, 2010). The app is available in the Oculus library for everyone to download free of cost, and incorporate in their curriculum.
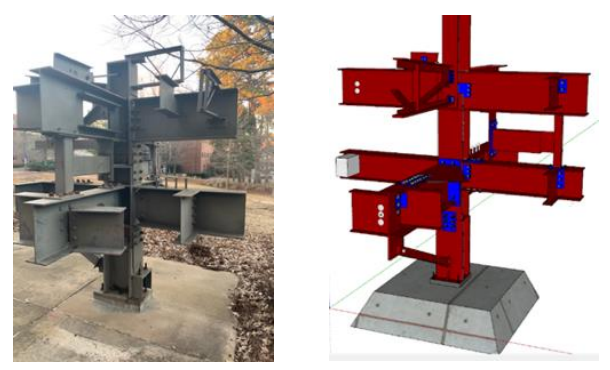

Figure 1. Steel Sculpture Physical Model (Left), Sketch-up model of Steel Sculpture (Right), Salman, A, 2019

\section{Research Design}

The purpose of this research study was to determine significance of replacing actual field trip with VFTs due to time, safety, and cost issues. To explore this idea the author developed the following research design:

Research Aim: To investigate if VFT's could replace or substitute actual field trip in times of need.

Research Objectives: 1)To examine and assess student learning through VFT's and actual field trip;2) To find out student perception of learning through VFT's versus actual field trip;3) To assess the challenges of learning through VFT's.

To conduct this study the following Research Hypothesis was developed: 
Alternate Hypothesis, $H_{A}$ : Students who participated in the actual field trip learn better than those who participated in VFT's.

Null Hypothesis, $H_{o}$ : There is no significant difference in student learning through the two ways of teaching.

In order to fulfil our research aim and objectives following Key Questions were established:

1. How can we measure student learning through the two pedagogies?

2. Can students achieve the same knowledge as achieved by an actual field trip?

3. What is student perception for replacing an actual field trip with VFTs?

4. Are there any challenges involved in adopting VR based pedagogy?

\section{Literature Review}

Visualization skill acquisition is an important aspect of engineering education. Along with math and science disciplines, engineering instruction has been identified as a discipline in which students have the most difficulty visualizing and understanding complex and abstract information (Salman, A, 2019). The importance of visualization skills in construction engineering education stems from the inherently spatial nature of construction projects (Nikolic et.al, 2011). Construction education requires the development of various skills to contribute efficiently in the professional field. VR and Augmented Reality (AR) technologies have proven beneficial in various disciplines. Technologies that add to the learning environment have gained popularity and have become the subject of even further studies. Many researchers in construction education are trying to bring the on-site field experience in classroom based education. For this purpose, Salman, 2019, explains the creation of SSA and workability of the app. Figure 2 shows some pictures from the app.

Azhar (2017) research introduces some case studies that show effectiveness of Virtual Reality in the construction industry. The researcher argued that the traditional safety planning relies heavily on manual observations. The case studies proved that the safety planning using Virtual Reality is more effective than the traditional safety training (Azhar et.al, 2017). Dawood et al. (2014) aims to utilize 4D enabled games for construction safety based on some created scenarios. The main purpose of the research was to demonstrate effectiveness of the 4D game for trainees to prevent hazards on the job site.(Dawood et.al, 2014). Kim, Leathem and Liu conducted a study which focused on learning construction processes through $360^{\circ}$ photography (Kim at.al, 2019). Their digital $360^{\circ}$ photography focuses on construction of foundation wall. Overall feedback from the students was satisfactory with some suggestions for improvements in 1) adding a visual schedule, 2) adding sound, 3) the ability to move freely within the panorama, 4) clearer images, 5) including videos (Kim, et.al, 2019).
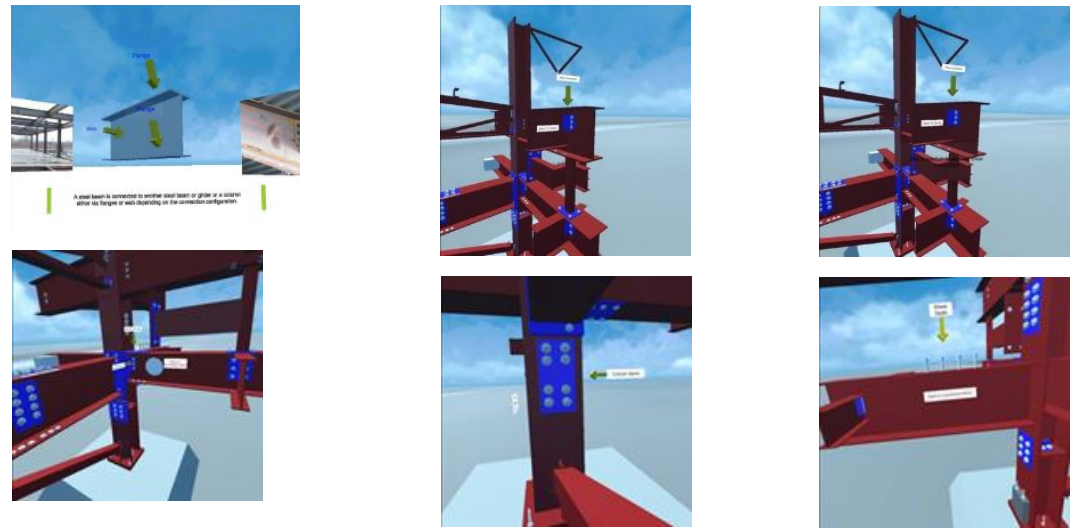

Figure 2. Images from Steel Sculpture App (SSA), Salman, A, 2019 
San Diego State University (SDSU) has started a Virtual, Immersive, Teaching, and Learning (VITaL) program, which provides a variety of VR, AR, and mixed reality (MR) immersive tools for use across the pedagogical spectrum. The VITaL program has served as an incubator to enable experiences that would otherwise be out of reach in a traditional learning environment. This program has resulted in increased student understanding, knowledge, skills and motivation (Huaze, et. al, 2019).

\section{Conclusions from Literature Review}

Although researchers have recognized the importance of field trips for students learning (Pereira \& Gheisari, 2017), however, there are many distractions on a construction site and difficult for the instructor to focus on the points to learn and observe. Moreover, to teach steel connections, the framing plan of the building should be visible which adds to the difficulty of selecting a productive site visit (Salman, A, 2019). Often times the result is no field trips which effects student's capability of making the right decisions once stepped into professional life. Educators need an alternative to actual construction site visit that can provide similar or better learning experience (Kim et.al, 2019)

Clearly, Virtual Field Trips (VFTs) cannot provide the physical perception that one has in the field, such as touching soil, walking on rubble, observing the chaos at a construction site etc. Nobody can challenge the benefits of an actual field trip. However, the literature review shows that many schools and researchers are using VR tools in different forms to aid both instructors and students. VR technology provides an opportunity to students to visualize the concept and are able to focus on the lesson specific topics without any distractions. Creating VR models provides a very positive contribution towards improving pedagogy and student understanding of spatial configuration of construction processes.

\section{Research Methodology}

In order to measure student perception of VFTs and learning assessment through the two methods, a framework was developed, explained in figure 4. The developmental phase of the SSA has been discussed in a previous published paper (Salman, A, 2019). A brief description of developmental phase of the app is given in figure 3. Below section briefly explains the content of the app. This paper focuses on, 1) Learning assessment through the SSA versus physical field trip, 2) students perception of replacing actual field trip with VFTs. Figure 4 describes step by step framework of this study.

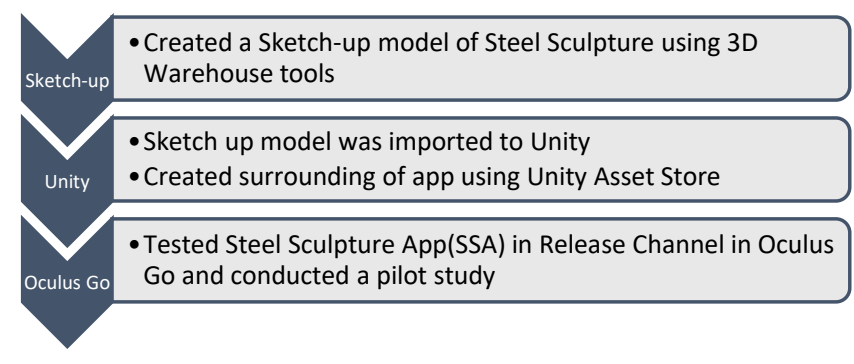

Figure 3. Development steps of the SSA

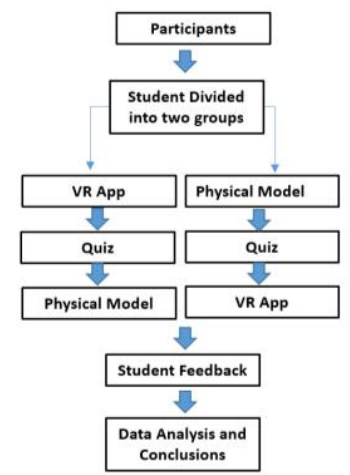

Figure 4. Steps of the Study

\section{Steel Sculpture App (SSA)}

A steel sculpture is a physical system that shows different types of connections found in standard construction practices as shown in Figure 1. A very exhaustive process of making a story board took place in which we determined and analyzed what content to present in the app and how to present it. 
We started off by making a sketch up model of the steel sculpture and shortlisted the connections we wanted to teach. Seven different modules represented seven different connections. All the programming and voice over was done in Unity and then imported to Oculus go to test it. Moreover, SSA, is also designed for people with hearing impairment. The publishing of the app had go through a series of content and technical review. It was finally published for everyone to download on September $23^{\text {rd }}, 2019$.

\section{Student Demographics}

The students that volunteered for this research were a mix of architecture and building science students. The study was conducted in summer 2019 and fall 2019. Fifteen students participated in the summer and 42 students participated in the fall study. All students were enrolled in BSCI Structures of Building-II. The results and analysis show assessment and feedback from 57 students. There were 33 architecture students and 24 building science students. There were 3 sophomores, 41 juniors, 11 seniors and 2 graduate students. Out of 57 students 34 were in the experimental group and 32 were in the controlled group.

\section{Measuring Student's Learning Assessment and Perception of VFTs}

To compare and assess students learning through the SSA and through physical field trip, a quiz was developed containing 10 simple questions related to steel connections (quiz in Appendix A). Students were divided into two sub-groups, controlled group and experimental group. Controlled group learnt through an actual field trip and took the quiz. The experimental group, using the Oculus Go, learnt through SSA and took the quiz. At the end, the results were compared and analyzed.

To get student perception and analyze if VFTs could replace an actual field trip, all students were given a chance to experience both methods of teaching. Student's feedback were taken in the form of survey which included a likert scale as well as some open ended questions. Students also provided feedback through informal interviews with the author.

\section{Results and Discussion}

To address first research questions, we designed a quiz to measure the student assessment. Participants from controlled group and experimental group took the quiz after the main instructions were given. The quiz results were analyzed to answer the second research question (Table-1 shows results of student assessment). The controlled group received instructions through the actual field trip, whereas, experimental group received instruction through VFT's. Overall mean of experimental group was 7.79 and the control group mean was 7.45. The mean value shows that students learning through VFT scored better. T-test was performed on the two groups of data, $\mathrm{p}<0.5$ which shows that there was

Table 1

\begin{tabular}{lcccccc}
\hline Student Assessment & & & & & & \\
\hline & $\mathrm{N}$ & Mean & $\mathrm{t}$ & $\mathrm{df}$ & $\mathrm{SD}$ & $\mathrm{p}$ \\
\hline Controlled Group & 32 & 7.45 & 1.08 & 30 & 1.28 & 0.28 \\
\hline Experimental Group & 34 & 7.79 & 1.08 & 63 & 1.25 & 0.28 \\
\hline
\end{tabular}

no significant difference in the two data groups. In addition to that, on comparing the quizzes of the two groups, it indicated that there were some questions which the controlled group got wrong but most participants in experimental group answered correctly. For examples, question 8 of the quiz (detail quiz with pictures in Appendix A), "Which of the following connections do you recommend when you need a shear-moment connection between a girder and column?". Four option were given and one was correct. In the controlled group, $88 \%$ of students answered correctly whereas in the experimental group $95 \%$ of students answered it correctly. This indicates that the students in the 
experimental group were able to get a deeper understanding of the subject matter. This may be due to undistracted instruction, being able to learn on their own pace, or better visualization. The average of the two group's also shows that students not only can achieve the same knowledge through VFTs but learn better since there is no disruption and the learner could observe the details at his/her own pace. In VFTs students is able to pause or repeat a module as needed.

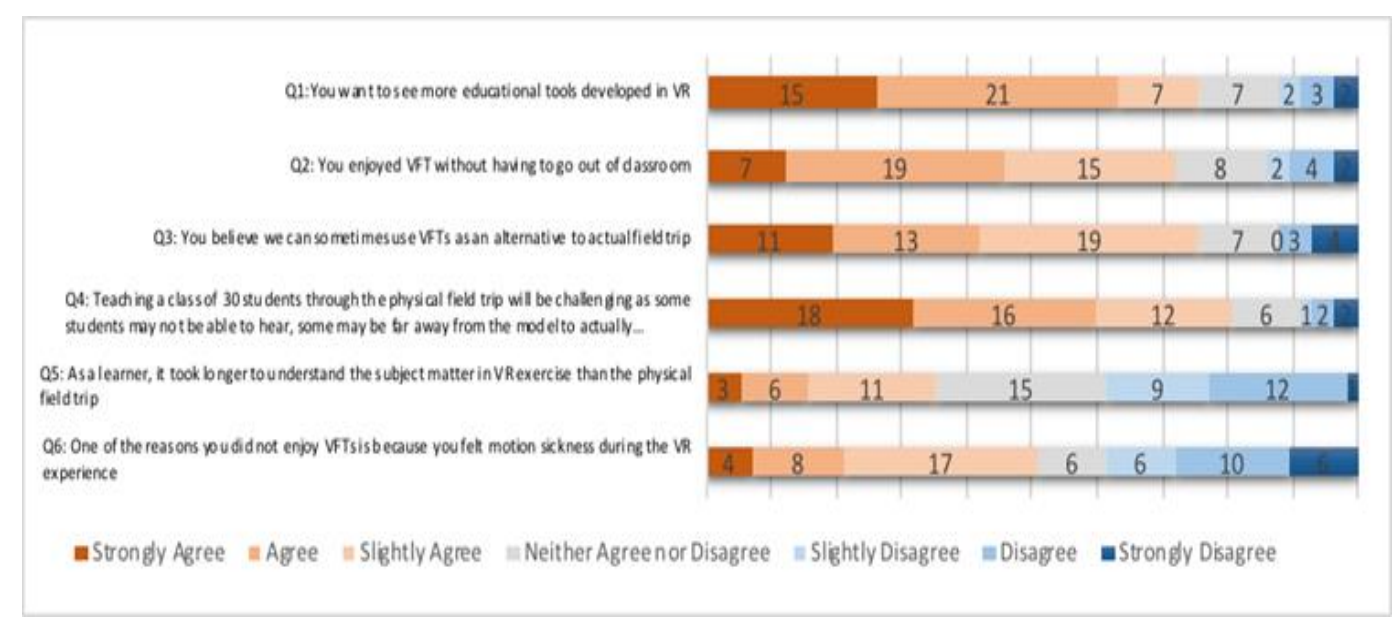

Figure 5. Student Feedback Survey

Table 2

Student Perception and Feedback

Strongly Agree $=7$ - Strongly Disagree $=1$

\begin{tabular}{|c|c|c|c|c|c|}
\hline Questions & $\mathrm{N}$ & Median & Mode & SD & $\begin{array}{l}\text { Weighted } \\
\text { Average }\end{array}$ \\
\hline $\begin{array}{l}\text { Q1:You want to see more } \\
\text { educational tools developed in VR }\end{array}$ & 57 & 6 & 6 & 1.61 & 5.40 \\
\hline $\begin{array}{l}\text { Q2: You enjoyed VFT without } \\
\text { having to go out of classroom }\end{array}$ & 57 & 5 & 6 & 1.53 & 5.02 \\
\hline $\begin{array}{l}\text { Q3: You believe we can sometimes } \\
\text { use VFTs as an alternative to actual } \\
\text { field trip }\end{array}$ & 57 & 5 & 5 & 1.66 & 5.05 \\
\hline $\begin{array}{l}\text { Q4: Teaching a class of } 30 \text { students } \\
\text { through the physical field trip will be } \\
\text { challenging as some students may } \\
\text { not be able to hear, some may be far } \\
\text { away from the model to actually } \\
\text { understand it well }\end{array}$ & 57 & 6 & 7 & 1.3 & 5.53 \\
\hline $\begin{array}{l}\text { Q5: As a learner, it took longer to } \\
\text { understand the subject matter in VR } \\
\text { exercise than the physical field trip }\end{array}$ & 57 & 4 & 4 & 1.51 & 3.93 \\
\hline
\end{tabular}




\begin{tabular}{llllll}
\hline Q6: One of the reasons you did not & 57 & 5 & 5 & 1.8 & 4.02 \\
enjoy VFTs is because you felt & & & & & \\
motion sickness during the VR \\
experience
\end{tabular}

To answer the 3rd and 4th research questions, a survey was developed. Figure 5 shows the questions and student feedback form the survey. Table 2 shows the median, mode, SD, and weighted average of the result received of the data received where strongly agree $=7$ and strongly disagree $=1$.

The 3rd question, "You believe we can sometimes use VFTs as an alternative to actual field trip", 43/57 students either slightly agree, agree or strongly agree to this statement. The weighted average is 5.05 , which shows that majority of people agree on that statement. Few students were using the VR Oculus Go headset for the first time for which they thought it took longer for them to understand the subject matter (Q5: weighted average=3.93). Some students also felt motion sickness during the experience (Table 2, Question 6, weighted average $=4.02$ ).

Students also want to see more educational tools developed in VR (Q1 figure 5 and Table 2, weighted average $=5.4$ ). However, an informal discussion with the participants reached a conclusion that there are some experiences for which we have to visit the actual site. Especially for freshmen and sophomores who have little field experience. However, for juniors and seniors VR based educational tools should be developed for conceptual clarity.

\section{Conclusions}

In this study we examine student assessment and perception of VFTs versus the actual field trip. A Steel Sculpture App (SSA) was created as the VFT and the location of the actual steel sculpture model was considered an actual field trip. The study was done in Structures of Building-II course and students had prior knowledge of steel connections and design. It was found that students not only learnt the same but better in VFTs than in the actual field trip. It was observed by the author during the actual field trip that students who were closer to the instructor were able to listen and see well whereas those at a distant were either distracted, not able to listen, or could not see the connection properly. VFTs gives students a chance to focus on subject matter very closely with visual demonstrations and applications.

The actual field trips entails a lot of planning on the instructor's part. However, there are some experiences for which the actual field trips are essential. Evidently, VFTs cannot provide the physical perception that one has in the field, such as touching soil, walking on muddy dirt, the sound and smell, or climbing the stairs of a construction site. A well-designed VFT, involving proper visualization, real time maps, sound and video clips in a variety of formats, could however help students imagine what an actual site visit would be like. In targeting the learning objectives through a VFT, one has to be realistic in its design, information presented and voice over. The SSA created for this study is an Oculus Go app and has been published for everyone to download from the Oculus library and incorporate it in their curriculum. After the study, students proposed some improvements in the app, which are under process.

Many of the students were using the Oculus Go for the first time. Majority of female students experienced motion sickness using the Oculus Go which is a lot reduced in Oculus Quest. Though students scored better with VFT but they still feel actual field trips are necessary, productive and comfortable to the eye. A student responds to an open ended question of whether we can replace an 
actual field trip to a VFT, "We can replace it but I believe we shouldn't unless very necessary. Handson learning is very necessary for students as it enables them to touch, feel and actually be present at the construction site. I don't encourage replacing it entirely. I encourage working on making these apps better to be used in some circumstances". Per the findings of this study students do want to see more educational apps developed in VR/AR/MR. It is a great tool and can save in-class time provided we have devices for all students in the class.

\section{Acknowledgement}

This research was made possible from the funding of McWhorter Fund for Excellence Award 2018. The author would like to thank Dongnyeonk Han, an undergraduate student who assisted in making the Steel Sculpture App(SSA).

\section{References}

A.H. Behzadan and V. R. Kamat, Enabling Discovery based learning in construction using telepresent augmented reality, Automation in Construction,33, 2013, pp.3-10

Azhar, S. (2011). Building information modeling (BIM): Trends, benefits, risks, and challenges for the AEC industry. Leadership and management in engineering, 11(3), 241-252.

Dragana Nikolic, S.M.ASCE; Shrimant Jaruhar; and John I. Messner, M.ASCE, 2011. Educational Simulation in Construction: Virtual Construction Simulator1. Journal of Computing in Civil Engineering, Volume 25 Issue 6 - November 2011

Hauze, S. \& Frazee, J. (2019). Virtual Immersive Teaching and Learning: How Immersive Technology is Shaping the Way Students Learn. In J. Theo Bastiaens (Ed.), Proceedings of EdMedia + Innovate Learning (pp. 1445-1450). Amsterdam, Netherlands: Association for the Advancement of Computing in Education (AACE). Retrieved September 11, 2019 from

Jeffery, Kim. Leathem, Tom. Liu, Junshan. (2019), Comparing Virtual Reality Modalities and $360^{\circ}$ Photography in a Construction Management Classroom" 55 $5^{\text {th }}$ ASC Annual International Conference Proceeedings. Pg 221-227

K.-Y.Lin, J.W.Son and E.M. Rojas, pilot study of 3D game environment for construction safer education, Journal of Information Technology in Construction, 16, 2011, pp.69-84.

M. Crosby-Nagy, J. Carfora, ICT Applications in US Higher Education, Giovanni Vincenti, James Braman (Eds.), Teaching through Multi-User Virtual Environments: Applying Dynamic Elements to the Modern Classroom, Information Science Reference (an imprint of IGI Clobal), 978-1-61692-8223 (2011), pp. 47-58

Nashwan Dawood, Geoff Miller, João Patacas, Mohamad Kassem , Combining Serious Games and 4D Modelling for Construction Health and Safety Training. 2014 International Conference on Computing in Civil and Building Engineering

R. Berka, J. Bittner, P. Slavik, VR and HCI Labs at the Czech Technical University in Prague, (Special Issue - VR and HCI Labs) SBC Journal on 3D Interactive Systems (ISSN: 2236-3297) vol. 2 (2) (2011) 6-9

Rieber, L. P. (1996). "Seriously considering play: Designing interactive learning environments based on the blending of micro worlds, simulations, and games." Educ. Technol. Res. Dev., 44(2), $43-$ 58.10.1007/BF02300540

Salman, A (2019), Pedagogical Transformations in Building Structures' Classroom: Immersing Students into a Virtual World for in-depth Understanding of Steel Connections. $19^{\text {th }}$ International Conference on Construction Application of Virtual Reality 13-15 November 
Sampaio, Z. A, Ferreira, Miguel, Rosaria, P. Danial, Martins,P. Octavio (2010). 3D and VR models in Civil Engineering education: Construction, rehabilitation and maintenance. Automation in

Construction, Vol19, pg. 819-828.

$$
\text { Appendix A }
$$

Virtual Steel Sculpture Quiz

Please answer the following questions from the best of your knowledge.

Question 1: Simple Connection are used to transmit forces

a)Shear Forces b) Bending Moment c) Both Shear and Bending Moment d) None of the above

Question 2: What is the purpose of moment connection?

a)To transfer bending moments b) To transfer bending moments and shear forces c) To transfer only the dead loads d) To transfer only the live loads

Question 3: In connecting beams to girders, when do we need to cop the beams?

a)When beams and girders are of same depth $b$ )When beams and girders of same length c) When beams have to connect with columns d)None of the above

Question 4:The size of each member, plates and bolts is determined by the magnitude of load applied.(True/False)

Question 5: Which of the following connections do you recommend to use when a beam is too long to be transported in a single piece and has to be spliced i.e. transported in two pieces and joined at the jobsite?

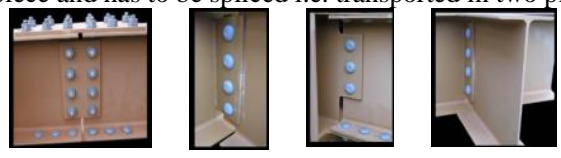

Question 6: Which of the following connections is Shear Tab?
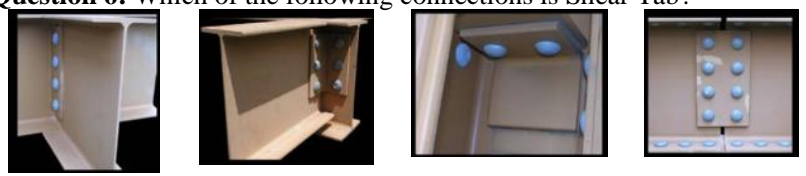

Question 7: Which of the following connection do you recommend to use when you have a concrete slab that is bonded to a beam and behaves as composite section?
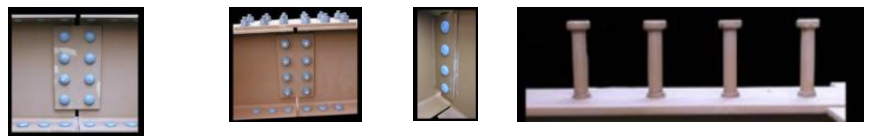

Question 8: Which of the following connections do you recommend when you need a shear-moment connection between a girder and column?
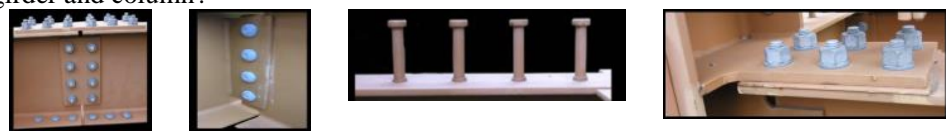

Question 9: Which of the following connections do you recommend when you need a shear-moment connection between a girder and column?
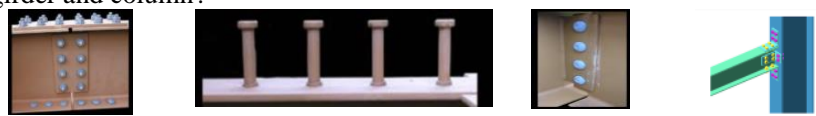

Question 10: Which of the following connection do you recommend when the column is too long to be transported in single piece and needs to be connected at the jobsite?
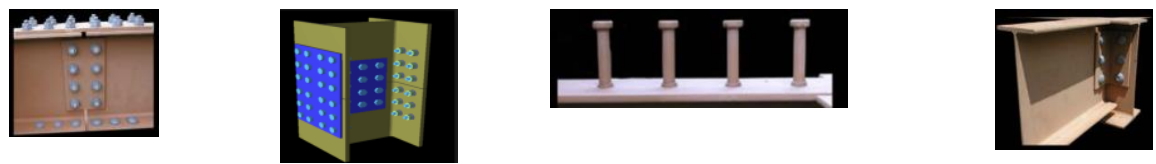